\title{
Machine learning can classify vital sign alerts as real or artifact in online continuous monitoring data
}

\author{
M Hravnak ${ }^{1 *}$, L Chen ${ }^{2}$, A Dubrawski ${ }^{2}$, D Wang ${ }^{2}$, E Bose ${ }^{1}$, G Clermont ${ }^{3}$, AM Kaynar $^{3}$, D Wallace ${ }^{3}$, A Holder $^{3}$, \\ MR Pinsky ${ }^{3}$
}

From ESICM LIVES 2015

Berlin, Germany. 3-7 October 2015

\section{Introduction}

Alarm hazards continue to be the top patient safety concern of 2015. Machine learning (ML) can be used to classify patterns in monitoring data to differentiate real alerts from artifact.

\section{Objectives}

To determine the degree to which ML, specifically random forest (RF), can classify vital sign (VS) alerts in continuous monitoring data as they unfold online as either real alerts or artifact.

\section{Methods}

Noninvasive monitoring data from 8 weeks of admissions in a 24-bed step-down unit (heart rate [HR], respiratory rate (RR; bioimpedance), oscillometric blood pressure (BP), peripheral oximetry $\left(\mathrm{SpO}_{2}\right)$ ) were recorded at $1 / 20 \mathrm{~Hz}$. VS deviation beyond stability thresholds (HR 40-140, RR 8-36, systolic BP 80-200, diastolic $\mathrm{BP}<110, \mathrm{SpO}_{2}>85 \%$ ) and persisting for $80 \%$ of a 5 min moving window comprised alerts. Of 1,582 alerts, 631 were labeled by a 4 -member expert committee as real alerts, artifact, or unable to classify. Alerts were: $R R$ 132 real, 25 artifact; BP 45 real, 40 artifact; $\mathrm{SpO}_{2} 181$ real, 93 artifact (HR alerts too few to analyze). Following feature extraction from expert-annotated alerts, we constructed a series of 10 moving windows of 3 min width each, and ending at $0,20,40,60,80,100,120,140,160$, and 180s from the time the VS first crossed alert threshold. The experiment is performed within a leave-onealert-out setup. In each iteration, one of the alerts is the

University of Pittsburgh, School of Nursing, Pittsburgh, PA, USA

Full list of author information is available at the end of the article test alert, and the rest are used as the training alerts. We trained the model using only the windows ending at 180 s after the time VS crossed the alert threshold from the training alerts (one for each VS), and then made predictions from each of the sliding windows on the test alert. We then computed area under the curve (AUC) scores by aggregating prediction at each test window.

\section{Results}

The RF classifier was able to discriminate between real $\mathrm{BP}$ alerts and artifact using information from the prior 3 min with an AUC of 0.8 in the 0s window, which improved to 0.86 for the window ending at 180s into the alert. SpO2 has an AUC of 0.88 for the 0s window, and improved to 0.96 at $180 \mathrm{~s}$ window. RR discrimination has an AUC of 0.73 at the 0 s window, and improved to 0.92 at the 180 s window.

\section{Conclusions}

A RF model trained on a small set of expert-annotated data was able to accurately classify $\mathrm{RR}, \mathrm{BP}$ and $\mathrm{SpO}_{2}$ alerts in monitored data as they are unfolding online as real or artifact to a helpful degree. $\mathrm{BP}$ and $\mathrm{SpO}_{2}$ did not improve much with more information gained after alert onset, while information gained as the alert continued to unfold improved RR discrimination. This approach holds promise to improve monitor alerting technology and clinical care.

\section{Grant Acknowledgment}

NIH NINR R01NR013912; NSF 1320347; NHLBI-K08HL122478. 


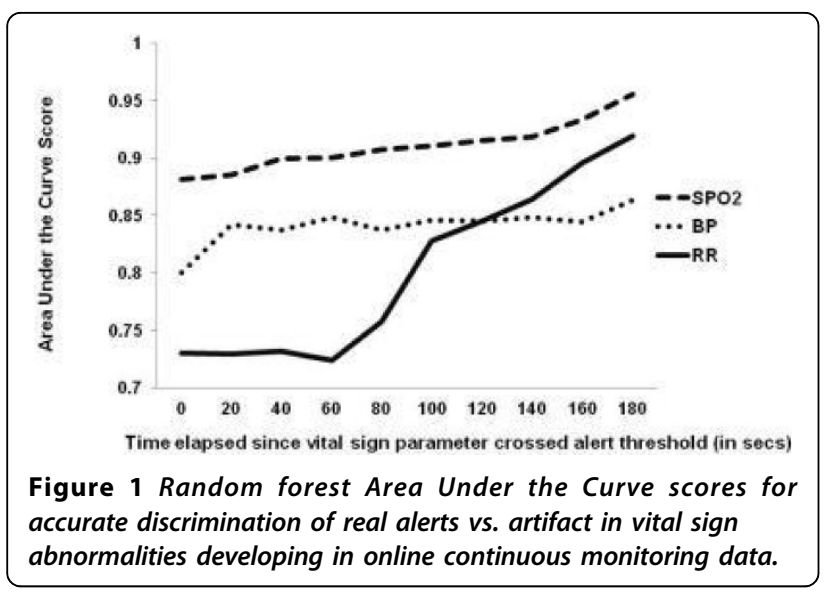

Authors' details

${ }^{1}$ University of Pittsburgh, School of Nursing, Pittsburgh, PA, USA. ${ }^{2}$ Carnegie Mellon University, Robotics Institute, Pittsburgh, PA, USA. ${ }^{3}$ University of

Pittsburgh, School of Medicine, Pittsburgh, PA, USA.

Published: 1 October 2015

doi:10.1186/2197-425X-3-S1-A550

Cite this article as: Hravnak et al:: Machine learning can classify vital sign alerts as real or artifact in online continuous monitoring data.

Intensive Care Medicine Experimental 2015 3(Suppl 1):A550.

\section{Submit your manuscript to a SpringerOpen ${ }^{\circ}$ journal and benefit from:}

- Convenient online submission

- Rigorous peer review

- Immediate publication on acceptance

- Open access: articles freely available online

- High visibility within the field

- Retaining the copyright to your article 